Scientists Starred 1903-1943 in "American Men of Science'

A Study of Collegiate and Doctoral Training, Birthplace, Distribution, Backgrounds and Developmental Influences. By Prof. Stephen Sargent Visher. Pp. xxiii+556. (Baltimore, Md. : Johns Hopkins Press ; London: Oxford University Press, 1947.) 25s. net. FOR forty-five years scientific workers of the United States have been starred for pre-emin. ence by their colleagues in the reference work "American Men of Science", first by a few outstanding leaders in twelve scientific subjects, and then by those who had already been starred. This volume gives an analysis of the life-histories of those who have been starred in terms of their scholastic and academic background, and such other factors as their birthplace, month of birth, reasons for taking up a scientific career and parentage.

So far as the relative share of various American academies is concerned, this study is of no particular interest outside the United States ; but a number of facts of more general interest emerge from the study. Thus we learn that more than three-fourths of the starred scientists have been employed by universities in recent years; also most starred scientists, for reasons that may well be in dispute, belong to the so-called upper classes, the highest percentage (one in seven) being fathered by Unitarian clergymen, the lowest (one in 196) by engineers. Cities are more likely to produce notable scientists than rural areas.

The statistical results given as to academic careers, however, must be considered as limited in their value when one finds among the starred physicists without a degree such a name as that of Einstein ; he presumably appears in this category as having no American degree. The best chance of becoming a starred scientist seems to lie with those born in March, with January, May and October some way behind. A study of the lists in the various subjects shows no obvious omissions; but on the whole a tendency to go slightly below the level which would probably be aimed at in a similar classification in Britain. The book provides a mine of information about American men of science as a whole, which may well interest the curious as well as the serious student.

\section{Children as Naturalists}

By Margaret M. Hutchinson. Pp. $184+9$ plates. (London : George Allen and Unwin, Ltd., 1947.) 7s. $6 d$. net. Margaret hutchinson is the grandI daughter of the late Sir Jonathan Hutchinson, who founded the Educational Museum at Haslemere. In 1931 she opened her own junior school at her parents' home, Yafflesmead, near Haslemere. The school flourishes amid acres of semi-wild garden, meadow and woodland, and in this setting an enthusiast has shown how children's interest in Nature may be fostered through exploration, discovery and intimate contact with living creatures.

"Children as Naturalists" is a record of Miss Hutchinson's work and a testimony to her enthusiasm. Three general chapters on "Exploring with the Kindergarten", "Adventures with the Sixes and Sevens" and the "Study of Environment with Juniors" are followed by seven others called "The Quest for . . .", mammals, birds, pond creatures, flowers, etc. There are some useful photographs and diagrams to illustrate the text and many practical hints about the making of apparatus, as well as some of the scientific information needed by the teacher but not easily found in elementary text-books.
All this will be useful to the junior school teacher; but Miss Hutchinson's obvious advantages-small classes, large and varied grounds and the fact that she herself is a scientifically trained and passionately enthusiastic naturalist - should make her sympathetic with all teachers of Nature study in junior schools who do not reach the high standards revealed in this little book.

T. H. HAWKIN S

\section{New Biology, 3}

Edited by M. L. Johnson and Michael Abercrombie. Pp. $176+24$ plates. (Harmondsworth : Penguin Books, Ltd., 1947.) $1 s$.

THE third volume of "New Biology" maintains 1 the standard of its predecessors. Addressed primarily to those who have a taste for scientific reading, this miscellany of essays aims at giving an up-to-date account of some aspect of biology which has excited contemporary interest. Contributions like "The Electron Microscope" and "Biological Research" by V. E. Cosslett are likely to be tough going for readers who know little about biology; but Alee Parker's article on "Beasts of Burden" will be as fascinating to the schoolboy as the savant. Articles on "How a Grasshopper becomes a Locust", "Forage Plants", "The Menace of the Roundworm", "Animal Life in Caves" and "Biology of Ship Fouling", indicate that the joint editors are well aware of those subjects which make popular reading.

\section{The Genetics of Garden Plants}

By M. B. Crane and W. J. B. Lawrence. Third edition. Pp. xvii +299 . (London: Macmillan and Co., Ltd., 1947.) 16s. net.

"CRANE and Lawrence" is now a standard text

1 for both students of biology and for practical gardeners. Indeed, it is one of the few books which fulfil a want both for the academic specialist and for the practical man. The third edition is different in some respects from the earlier editions; parts of some chapters have been rewritten, and the subjects of xenis and polyploidy receive greater attention in special chapters. One criticism of the earlier editions was that the elementary introduction to genetics was too condensed for the non-specialist. By some clever and subtle writing the authors appear to have largely overcome this criticism in the third edition. Through fully annotated descriptions of research results, the book is an invaluable guide to the recent literature on horticultural plant genetics. F. W. SANSOME

\section{Territory in Bird Life}

By Eliot Howard. New edition. Pp. 224 +11 plates. (London and Glasgow: Wm. Collins, Sons, and Co., Ltd., 1948.) 10s. 6d. net.

A FRESH edition of Eliot Howard's classic book A on "Territory in Bird Life" is indeed welcome, for it has long been difficult to obtain a copy of a work that every ornithologist should read. Published in 1920, it put forward the theory, supported by the author's many and painstaking observations, that the chief pivot of bird-life was territorial, nearly all birds needing to secure and hold a territory as a basis of their sexual activity and breeding cycle. This seemingly simple theory was found to have far-reaching implications, and to throw light on many aspects of bird behaviour ; indeed, its importance has become more and more apparent with the passing of the years. It is good to have this new edition of so important a book.
Frances Pitt 